\title{
Evaluating the Efficacy of Virtual Dissector Technology Implementation In Undergraduate Anatomy.
}

\author{
Jonah Persinger ${ }^{1}$, Stacey Dunham², Polly Husmann ${ }^{2}$ \\ ${ }^{1}$ Indiana University School of Medicine - Bloomington Campus, ${ }^{2}$ Indiana \\ University School of Medicine, Department of Medical Sciences.
}

\section{Background and Hypothesis:}

At the graduate and professional level, computer-aided instruction demonstrated a positive impact on knowledge gains when supplementing traditional teaching methods (Wilson et al). The present research sought to determine the efficacy of supplementing traditional pedagogical methods in an undergraduate anatomy lab with VH Dissector Software (VHD) on a large touchscreen terminal.

\section{Experimental Design or Project Methods:}

Throughout Basic Human Anatomy (ANAT-A215), students took a pre-quiz before covering a topic followed by a post-quiz in the next class. Using VHD was the intervention, while using the traditional lab manual, models, and two prosected cadavers was the control. The mean difference between pre-test and post-test scores was calculated. Independent Samples T Tests compared the mean difference between intervention and control groups.

Post-course surveys were obtained. Calculations were made of frequencies for each question and Spearman Rho correlations between questions.

\section{Results:}

There was significant improvement in scores with the intervention (versus control $)$ in the Spring 2019 semester $\left(\right.$ Mean $_{\text {intervention }}=1.13$, Mean $_{\text {control }}=0.92, P$ $<0.01)$. In the post-course survey, $54.1 \%$ of students indicated that they would not recommend using VHD in future semesters. Among these students, 50.1\% stated they did not find VHD beneficial, 34\% stated VHD helped to rotate structures, and $23.4 \%$ stated VHD was a change of pace from other lab responsibilities. Among the students that recommend using VHD, 64.8\% stated VHD helped to rotate structures, $51.4 \%$ stated VHD provided context for what they saw on models, and $48.9 \%$ stated that VHD was a change of pace from other lab responsibilities. A significant correlation was found between enjoying use of the VHD and perception of learning using VHD $(r=0.794, P<0.01)$

\section{Conclusion and Potential Impact:}

These results indicate a benefit to supplementing traditional anatomy learning modalities with dissection software at the undergraduate level. Yet, while students recognize a benefit, they often recommended not using the tech in future semesters. 
1. Wilson $\mathrm{AB}$, Brown $\mathrm{KM}$, Misch J, Miller $\mathrm{CH}$, Klein BA, Taylor MA, et al. Breaking with Tradition: A Scoping Meta-Analysis Analyzing the Effects of StudentCentered Learning and Computer-Aided Instruction on Student Performance in Anatomy. Anatomical Sciences Education. 2018;12(1):61-73. 